\title{
Indexing and Impact Factor: Judging the Quality of a Journal
}

\section{Amit Kumar Koushik*}

Department of Biotechnology, Center for Post Graduate Studies, Jain University, Jayanagar, Bangalore 560011 , India

\begin{abstract}
To increase visibility, availability, and readership of a journal, its publication must be indexed by one or more leading databases. The quality of a journal can be measured by assessing the indexation of that particular journal. Among various indexing databases, PubMed, EMBASE, EBSCO, SCOPUS, MedLine, SCIRUS are few main databases. Before choosing a database, it is important to understand the features it provides and the field of publication. IF do not tell us as much as some people may think about the respective quality of the science that journals are publishing. Regardless of a journal indexed in prominent databases, it is not necessary that the journal will have an IF. However, it is certain that IFs are still a standard administrators and researchers worldwide as a criterion to judges the quality of a journal, or even the quality of information or an individual. IFs will exist for a long time.
\end{abstract}

Keywords: Impact factor; Indexing; Journal; Quality; Database

\section{Introduction}

To stand out from the crowding publications, it is very important for a journal's publications to get indexed in one or more leading databases. It helps a journal to be considered as authentic and effective scientific information [1].

When a publication gets indexed in a database, it is readily available for the readers. However, many databases do not provide full access to the articles. Among various indexing and abstracting databases, some are provided by the publishers, for example, Scopus, while some are managed by The United States National Library of Medicine (NLM) at the National Institutes of Health such as PubMed [2]. Regardless of which databases you select, a formal application is required for inclusion in that particular database. It is better for a journal to get indexed in different platforms; it gives more visibility to the journal and availability to the readers [3].

\section{History of indexation}

The quality of a journal can be measured by the indexation of the journal. It is believed that an indexed journal contains high-quality articles compared to a nonindexed journal. However, there is debate over the indexation of medical journals. Initially, Index Medicus (IM), in 1879, was a comprehensive bibliographic index, which later evolved into the NLM. In the 1960s, the NLM created MEDLARS, a bibliographic database, which later became MEDLINE. With time, due to the dissemination of home internet connections and launch of the Web and web browsers, MEDLINE evolved into Entrez and PubMed [4].

\section{Impact factor}

With the issue of debatable indexation process, another controversial issue arose was impact factor (IF). IF is used to represent the importance of a particular journal in a specific area. IF is calculated for the journals indexed in Thomson Reuters, based on the journal citation reports. However, there is debate over the calculation of the IF and has been disapproved for the improper application. Calculation of IF can be erred by different factors, including improper citation reports, the online presence of the article, negative citations, types of the articles in that particular journal, the the frequency of the publication issues, subject areas, and the the presence of influential journal editors.

Regardless of a journal indexed in prominent databases, it is not necessary that the journal will have an IF. Similarly, it is not necessary that a journal indexed in PubMed or Medline will be indexed in Thomson Reuters Journal Citation Reports. In addition, the journals indexed in Thomson Reuters Journal Citation Reports with an IF do not necessarily get indexed in PubMed or Medline [1,5-7].

\section{The question}

We face a question: which is the most valid indexation and how to compare the quality of the published articles? The reason behind this question is the ever increasing numbers of authors who are interested in publishing articles, as the importance of publication is now being increasingly recognized by the institutions. Also, in many countries including India, Medical Council of India has recommended indexed publications for the professors in medical colleges [8].

Now, there is dilemma among authors that whether they should choose journals, which are indexed in PubMed, EMBASE, EBSCO, SCOPUS, MedLine, SCIRUS etc. or go for the journals that have high impact factors, although not indexed in prominent databases. Also, the advent of many databases such as Index Copernicus, DOAJ, Open J Gate, Ulrich's International Periodical Directory, Hinari, Caspur, Genamics Journal Seek, Primo Central, Pro Quest, SCOLOAR, SIIC databases, Summon by Serial Solutions, Expanded Academic ASAP etc. has caused confusion. ${ }^{1}$ Are these indexation services relevant and can we call a journal "indexed" if they are indexed in these databases?

All the above questions need to be answered. All the national or international committees can play an important role in solving this problem.

\section{Impact factor as a measure of quality?}

The validity of IF as a measure of quality, especially for medical journals should be assessed. This can be done by testing the association of journal quality rated by researchers with the IF of that particular journal. A study by

*Corresponding author: Amit Kumar Koushik, Department of Biotechnology, Center for Post Graduate Studies, Jain University, Jayanagar, Bangalore 560011 , India, Tel: 91-9538955752; E-mail: koushikamit49@gmail.com

Received September 07, 2017; Accepted September 13, 2017; Published September 15, 2017

Citation: Koushik AK (2017) Indexing and Impact Factor: Judging the Quality of a Journal. J Health Med Informat 8: 285. doi: 10.4172/2157-7420.1000285

Copyright: ( 2017 Koushik AK. This is an open-access article distributed under the terms of the Creative Commons Attribution License, which permits unrestricted use, distribution, and reproduction in any medium, provided the original author and source are credited. 
Citation: Koushik AK (2017) Indexing and Impact Factor: Judging the Quality of a Journal. J Health Med Informat 8: 285. doi: 10.4172/21577420.1000285

Page 2 of 2

Saha et al. observed a strong correlation between IF and physicians' ratings of journal quality. The correlation was higher for the research group than for the practitioner group. They concluded that IF may be a reasonable indicator of quality for general medical journals [6].

It cannot be denied that attempts to quantify the quality of science are always difficult, and the journal IFs are among the few numbers to persist. It is also a truth that the IF is taken as a measure of citation rates for the journal. However, for many other journals, it is not. It is also a fact that IF is influenced by a small minority of papers of a particular journal. Therefore, IF cannot tell us about the quality of the science that journals are publishing. Moreover, the citation rate of papers also varies sharply between disciplines. For example, immunology articles published in Nature (2003) have received 50-200 citations and most of these citations were in cancer and molecular and cell biology (50-150 citations). On the other hand, papers in physics, paleontology, and climatology typically achieved fewer than 50 citations. Clearly, these reflect differences in disciplinary dynamics, not in quality [5].

Other factors are the type of content or the type of articles. Review articles are typically the most highly cited; however, citations of commentaries, news features, and news \& views articles had fewer citations.

\section{Conclusion}

IF do not tell us as much as some people may think about the respective quality of the science that journals are publishing. Neither do most scientists judge journals using such statistics; they rely instead on their own assessment of what they actually read.

However, it is certain that IFs are still a standard administrators and researchers worldwide as a criterion to judges the quality of a journal, or even the quality of information or an individual. IFs will exist for a long time.

\section{References}

1. Balhara YPS (2012) Indexed journal: What does it mean? Lung India 29: 193.

2. Masic I, Milinovic K (2012) On-line biomedical databases-the best source for quick search of the scientific information in the biomedicine. Acta Informatica Medica 20: 72-84.

3. Akhigbe RE (2012) Scientific journals: Indexation and impact factor. Lung India 29: 300-301.

4. Garfield E (2006) The history and meaning of the journal impact factor. JAMA 295: 90-93.

5. http://www.nature.com/nature/journal/v435/n7045/full/4351003b html?foxtrotcallback=true

6. Saha S, Saint S, Christakis DA (2003) Impact factor: a valid measure of journal quality? Bull Med Libr Assoc 91: 42-6.

7. Gasparyan AY, Ayvazyan L, Kitas GD (2013) Multidisciplinary Bibliographic Databases. J Korean Med Sci 28: 1270-1275.

8. Aggarwal R, Gogtay N, Kumar R, Sahni P (2016) The Revised Guidelines of the Medical Council of India for Academic Promotions: Need for a Rethink. Indian Pediatr 53: 23-26. 